This PDF is a selection from an out-of-print volume from the National Bureau of Economic Research

Volume Title: Behavioral and Distributional Effects of Environmental Policy

Volume Author/Editor: Carlo Carraro and Gilbert E. Metcalf, editors

Volume Publisher: University of Chicago Press

Volume ISBN: 0-226-09481-2

Volume URL: http://www.nber.org/books/carr01-1

Conference Date: June 11âf“"12, 1999

Publication Date: January 2001

Chapter Title: Environmental Information and Company Behavior

Chapter Author: Domenico Siniscalco, Stefania Borghini, Marcella Fantini, Federica Ranghieri

Chapter URL: http://www.nber.org/chapters/c10611

Chapter pages in book: (p. $251-280)$ 


\title{
Environmental Information and Company Behavior
}

\author{
Domenico Siniscalco, Stefania Borghini, \\ Marcella Fantini, and Federica Ranghieri
}

\subsection{Introduction}

Environmental policy is traditionally based on two sets of tools: (1) command and control regulations; and (2) economic or market instruments, such as environmental taxes, emissions charges, and tradable permits. The two sets of instruments have been adopted in subsequent waves, partly in response to economic analysis that shows command and control environmental policies are not cost-effective or are incapable of achieving the desired objectives in many circumstances.

In the last few years, some policymakers, the business community, and the media have increasingly emphasized the role of information-based environmental instruments. Such instruments, which are typically voluntary, range from company environmental reports to environmental audit and management schemes, such as International Standards Organization (ISO) 14000, Eco Management Audit Scheme (EMAS), and related award and compensation systems.

Information-based environmental policies are the subject of a lively debate. Their supporters claim that environmental reports and environmental management schemes are fundamental instruments for achieving the

Domenico Siniscalco is professor of economics at the University of Torino and director of Fondazione Eni Enrico Mattei. Stefania Borghini is a researcher at Fondazione Eni Enrico Mattei. Marcella Fantini is a researcher at Fondazione Eni Enrico Mattei and a lecturer at the University of Bergamo. Federica Ranghieri is a researcher at Fondazione Eni Enrico Mattei.

The authors are grateful to Kevin A. Hassett and other conference participants for their helpful comments. Special thanks go to Carlo Carraro and Gilbert Metcalf for encouraging the publication of a work which is still in a seminal form. The usual disclaimers, more than ever, apply. 
desired environmental quality. Their critics claim they are only "greenwashing," basically ineffective and devoid of any real effect.

This paper tries to shed some light on companies' behavioral responses to information-based environmental policies, dwelling on two building blocks: an original database at the company level collected by Fondazione Eni Enrico Mattei (FEEM) since 1995, and some recent literature on information and incentive schemes in companies.

This paper is divided into seven sections. Sections 8.2 and 8.3 briefly describe the main information-based environmental management tools and recall the theoretical rationale for their adoption; section 8.4 describes the database and identifies a subset of homogeneous companies in three polluting industries: (1) oil and gas, (2) petrochemicals, and (3) power generation. Sections 8.5 and 8.6 present some empirical results on the relation between information-based environmental strategies, economic performance, and environmental performance at the company level. Section 8.7 contains some concluding remarks.

The paper presents preliminary work that needs refinement. Information-based environmental policies are still in their infancy and their history is too recent to allow for a sound econometric analysis. The existing data and the relevant theory, however, seem to support the hypothesis that information-based environmental policies are indeed an instrument for changing company behavior and implementing environmental policies and regulations.

\subsection{The Theoretical Background}

In the textbook institutional setting, governments set environmental standards and companies comply. In addition to this, companies try to follow sound environmental strategies in order to avoid litigation and the emergence of future environmental liabilities. In some industries, such a strategy may also establish a good environmental reputation, which can be a powerful tool in their relationship with consumers, communities, and environmentalists. In the two latter cases, far-sighted companies may even exceed environmental standards.

In the situation we have just described, information plays a crucial role. In a world with imperfect information, regulators, investors, consumers, and other stakeholders want to know the companies' environmental performance, the achieved results, and the remaining problems and the schedule to solve them. Companies, symmetrically, need to communicate their environmental strategy and performance, in order to deal with their shareholders, stakeholders, and regulators. Against this background, the communication aimed at the external stakeholders has been widely discussed in the recent literature (Musu and Siniscalco 1993; Tietenberg 1997; Lanoi, Laplant, and Roy 1997; Khanna and Damon 1999; McIntosh et al. 
1998). The same flow of environmental information, moreover, can play a key role in reshaping company behavior, and this is the focus of our paper.

A useful starting point can be found in two papers, Brehn and Hamilton (1996) and Pfaff and Sanchirico (1999), which claim that the lack of internal information (i.e., ignorance) is often responsible for the noncompliance with environmental regulation by big companies and for their wrong assessment of environmental damage, hence, the need for information tools and self-audit. The issue, however, is more complex than this.

For many years, companies (as well as regulators and the general public) have somewhat neglected environmental issues, concentrating their efforts on economic and financial performance. But neglecting environmental standards, particularly in the traditional industries, has gradually created hidden liabilities that can seriously harm shareholders' value through various channels: trials and litigation about health, safety, and pollution; loss of reputation with clients and consumers; conflict with local communities and environmental groups; and so forth. Such new issues, which are well known to shareholders and companies' chief executive officers, require a change in company behavior that can be pursued using an informationbased environmental strategy that aims at changing company behavior through appropriate flows of information, audit, and incentives (SinclairDesgagné and Gabel 1997; Pendergast 1999).

Given the nature and the objectives of information-based environmental strategies, governments and regulators too have a clear interest in promoting their standardization and wide adoption, sometimes proposing guidelines themselves to define such schemes and make them mandatory. In such cases, we can refer to information-based environmental policies.

\subsection{Some Information-Based Environmental Management Tools}

The best-known environmental management tool adopted by firms is the corporate environmental report (CER) published annually by companies to audit and communicate the most relevant environmental issues related to their operations (emissions, effluents, wastes, and expenditure and investment in the environmental area).

The number of companies publishing environmental reports has been rapidly growing from 1992 to 1998 (fig. 8.1). Data show that the release of environmental information, which actually began in 1990, was started by firms in highly polluting industries, such as chemicals and oil and gas. But environmental reporting quickly spread to other industries such as the automotive and transportation industries, telecommunications, electronic appliances, financial services, and consumer goods.

As previously mentioned, the quality of published environmental reports can vary substantially across companies and time. The earlier reports typically included many statements and very few data, typically referring 


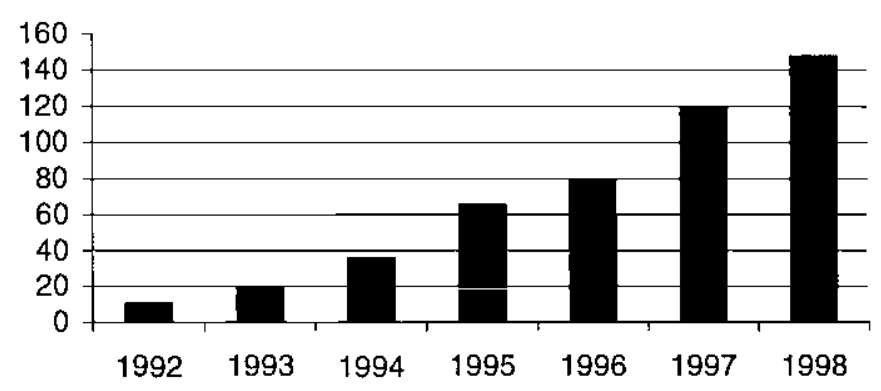

Fig. 8.1 Number of companies producing CERs worldwide, 1992-98 Source: ERM (1999).

to hot spots in the company operations, while recent reports include most comprehensive environmental data, together with environmental indicators and analyses that usually cover all the companies' activities.

In order to conduct a quality analysis, a specific rating system has been defined by FEEM within the Environmental Reporting Monitor (ERM) and published regularly since 1997 (see appendix C). If we adopt such system we can easily see that the quality of environmental reports has been constantly increasing (fig. 8.2).

Following the publication of CERs in the mid-1990s, companies began to introduce more sophisticated environmental audit systems aimed at promoting continuous improvements in the environmental performance of their operations. In order to facilitate and standardize the implementation of such audit systems, in 1993 the European Commission adopted the EMAS regulation. This scheme recommends voluntary participation by companies and gives them guidelines, with the objective of promoting better environmental performance at the site level. Similarly, worldwide the International Standards Organization launched the ISO 14000 scheme for the certification of corporate environmental management ${ }^{1}$ at the company level.

Since the mid-1990s, the number of companies that certify their environmental management systems for EMAS and ISO 14000 has been constantly increasing. Since 1996, the year of the publication of the first five ISO 14000 standards, 10,439 companies have been certified. Since 1993, more than 2,790 sites have been certified for EMAS. A similar growth can be seen in our sample (fig. 8.3).

In addition to CERs and auditing schemes, other management tools, such as compensation programs and award schemes, have been gradually introduced by many big companies in order to link environmental performance to economic incentives. In this respect, the adoption of award and compensation programs related to environmental results can be viewed as

1. It should be remembered that the first national standard on environmental management was the BS 7750, developed in the United Kingdom in the early 1990s. 


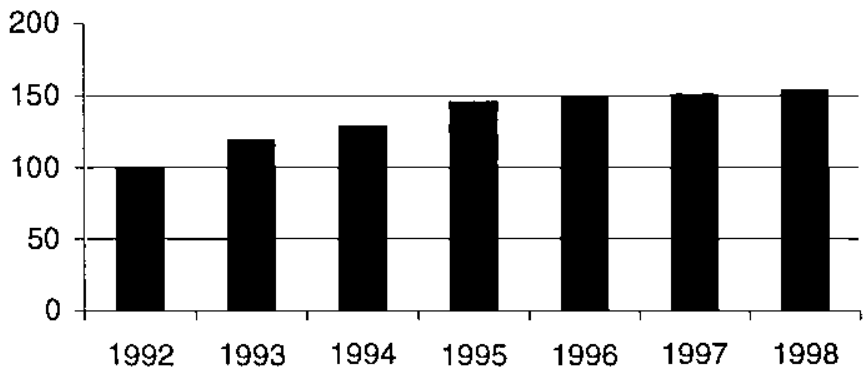

Fig. 8.2 Average quality of CERs $(1992=100)$ worldwide, 1992-98

Source: ERM (1999).

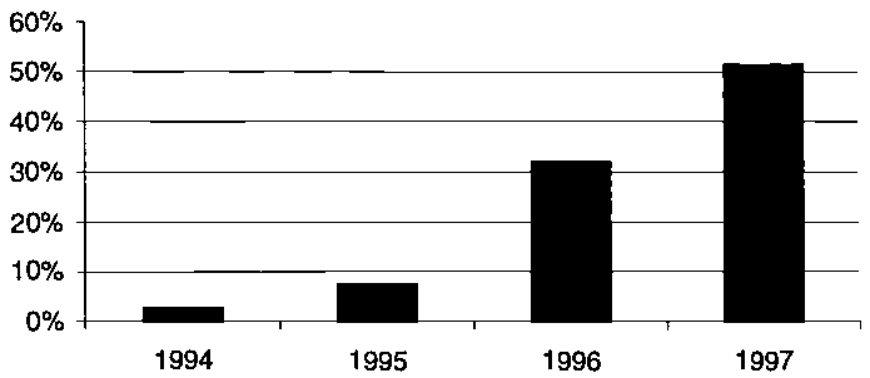

Fig. 8.3 Percent of EMAS or ISO 14000-certified companies worldwide, 1994-97 Source: ERM (1999).

an incentive-compatible strategy for integrating environmental issues into the company's management. Compensation and award schemes quickly spread and now they are common practice for almost all big companies. In our sample, the percentage of companies that implemented a compensation program increased from 32 percent to 73 percent from 1994 to 1997 (fig. 8.4).

From the theoretical point of view, environmental reports, audit schemes, and compensation mechanisms can be viewed as components of an integrated information-based environmental strategy aimed at changing company behavior. Let us see how these instruments work by analyzing an appropriate database at the company level.

\subsection{The Database}

Our database covers 476 CERs published worldwide from 1993 to 1997. To carry out a meaningful empirical analysis, we selected a sample that includes 39 big firms, based in 16 countries, belonging to three highly polluting industries that produce comparable emissions (such as $\mathrm{NO}_{\mathrm{X}}$ and 


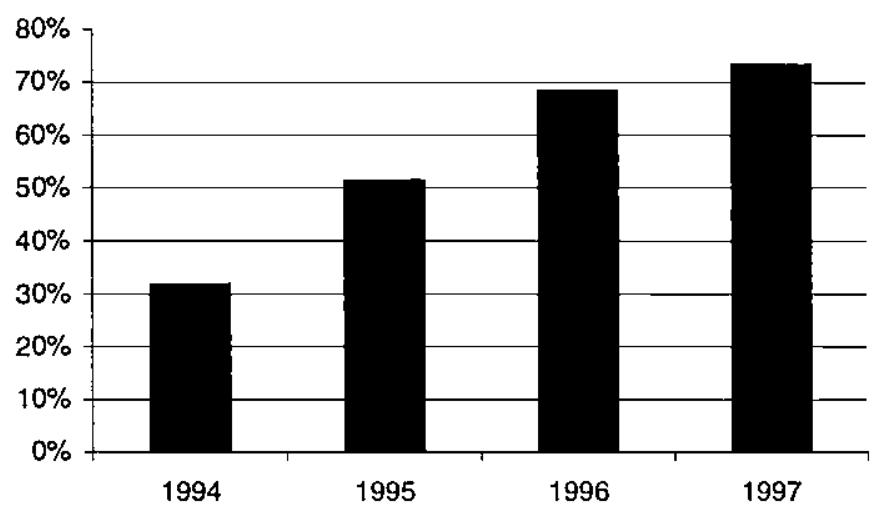

Fig. 8.4 Percent of companies adopting compensation programs and award schemes, worldwide, 1994-97

Source: ERM (1999).

$\mathrm{SO}_{\mathrm{x}}$ ) using similar feedstocks: (1) petrochemicals, (2) oil and gas, and (3) electric power generation (see appendix A) for the period 1993-97.

In addition to the CERs we gathered information on whether the companies adopted an environmental management system (i.e., ISO 14000 and/ or EMAS), adopted environmental compensation and award schemes, and collected data on the main economic variables at the company level (this was extracted from the standard annual reports).

Starting from this data, we built a panel that includes several variables: (1) a standardized index of pollution; (2) measures of the size and economic performance of the company; (3) an indicator of the quality, comprehensiveness, and transparency of the environmental information; (4) an indicator of the adoption of one or more environmental audit, compensation, or award schemes; and (5) several control variables at the company, industry, and country levels (see appendix A).

The panel is obviously affected by a sample selection bias because it includes only companies that voluntarily decided to publish CERs. Our analysis, however, focuses on the effects of more detailed instruments in this population of relatively caring industries. ${ }^{2}$ In this case the sampleselection critique does not apply because publishing a CER does not imply the adoption of the environmental management tools we are considering.

The environmental performance variable (LPOLL) is defined on an annual basis as $\mathrm{SO}_{\mathrm{x}}$ plus $\mathrm{NO}_{\mathrm{x}}$ emissions per unit of output. ${ }^{3}$ The indicators

2. Although in this case, our sample has no sample selection bias, it is worth noticing that, while data for environmental information accuracy are available for the whole period under consideration (1993-97), for more recent tools such as the environmental audit, compensation, and award systems the sample includes many zeros in early years.

3. The output is expressed in tons of oil equivalent (TOE), which seems to be a suitable measure in the three industries under review. 
have been chosen on the basis of their impact on the environment and on data availability. $\mathrm{SO}_{\mathrm{x}}$ is a main indicator used by the regulators as a base for the environmental taxation system, and $\mathrm{NO}_{\mathrm{x}}$ plays a major role in land acidification. At this stage, we cannot consider data on waste and water discharges because classification across countries and regulations on waste have significantly changed over the last 5 years, and the currently available data do not account for the damage associated with different discharged pollutants (a firm emitting a large quantity of a relatively harmless substance would be ranked as a larger polluter than another firm emitting a small quantity of a very toxic substance).

The size of the company (WORK) is proxied by the number of employees, which also indicates the complexity of the agency problems in the organization, while the economic performance (OPERATING INCOME) is measured by the operating income in current U.S. dollars. ${ }^{4}$

The quality of the information disclosed in the environmental reports (INFO) is measured by a scoring system, developed by the ERM at FEEM (see appendix B). The system evaluates the descriptive information contained in the report (i.e., mission, objectives, strategy, organization, and programs), the quality of environmental variables and indicators (e.g., some reports contain data on emissions but omit economic data, such as defensive and environmental expenditure, while others include indicators but do not publish raw data for emissions, effluents, and wastes), and the thoroughness of the report (e.g., many reports cover a subset of sites or ignore some foreign countries where the company operates).

Information-based environmental management is measured by a $0-3$ index (environmental audit, award, and compensation; EAC), which is the sum of three dummy variables: the first (E) records the adoption of EMAS and/or ISO $14000 ;{ }^{5}$ the second (A) records the existence of an environment-related award system, which does not give immediate benefits but directly influences the future career of the managers and the employees; and the third $(\mathrm{C})$ records the adoption of an environment-related compensation scheme. ${ }^{6}$ A more detailed description of the variables we use in our analysis can be found in table 8.4 , later.

We are well aware that both company variables and indicators are rather

4. We used companies' annual reports to collect data on their operating income. Unfortunately, most financial statements are expressed only in local currency. In order to make them comparable we decided to convert all financial variables into current U.S. dollars by using the nominal exchange rate of the local currency against the dollar.

5. Data on companies' environmental management certification were obtained from the EMAS official register and ISO 14000-competent body in each country.

6. To gain information about environmental compensation programs and award schemes we relied on CERs and annual financial reports and, for U.S. listed companies only, also on official disclosure required by the U.S. Securities and Exchange Commission (reports such as $10 \mathrm{~K}$ for American companies quoted on the New York Stock Exchange and 20F for nonAmerican companies quoted on the New York Stock Exchange). If this information was not available in corporate publications, we directly interviewed companies' environmental managers and external relation managers. 
raw and must be improved, but CERs have not been published for very long and the data we can collect are quite limited. In addition to company data, some control and regulation data have been collected at the country level.

\subsection{A First Look at the Data}

Do information-based environmental policies work? How do they influence company behavior? Some preliminary answers to such questions can be found by broadly comparing companies that adopted some information-based environmental strategies (henceforth EAC companies) between 1993 and 1997 with companies that did not adopt such schemes.

At a first glance, we observe that on average the companies that have implemented compensation and award schemes and have certified environmental management systems present better environmental performances. A $t$-test performed on the mean shows that although the difference is not significant at the standard 5 percent or 10 percent levels (except for 1997), EAC companies do perform better (table 8.1). Table 8.2 reports the average pollution growth rates for EAC companies versus the whole sample year by year. Once again, EAC companies are observed to perform better, as their average pollution rate is lower than the one for the whole sample for two out of the three years. When we consider average pollution rates (see fig. 8.5), we observe that EAC companies pollute much less than the total sample; and they reduce pollution throughout the time span we considered, while for the whole sample pollution drops from 1994 to 1996 but has an upward trend between 1996 and 1997.

To clarify this point we select three important case studies from among the companies in our sample: BP Chemicals (petrochemicals); ELF (oil

Table 8.1 Average Pollution Rates

\begin{tabular}{lllll}
\hline & 1994 & 1995 & 1996 & 1997 \\
\hline EAC $=0$ & 0.0038 & 0.0028 & 0.0036 & 0.0052 \\
EAC $>0$ & 0.0014 & 0.0011 & 0.0009 & 0.0007 \\
$t$-test & 0.78 & 0.81 & 1.34 & 1.87 \\
\hline
\end{tabular}

Table 8.2

Average Pollution Growth Rates

\begin{tabular}{lllll}
\hline & & & & \multicolumn{1}{c}{ Average } \\
& $1994-95$ & $1995-96$ & $1996-97$ & $1994-97$ \\
\hline Whole sample & -0.39688 & -0.086121 & 0.068504 & -0.1618 \\
EAC & -0.20206 & -0.21496 & -0.14913 & -0.18921 \\
\hline
\end{tabular}

Source: See appendix D. 


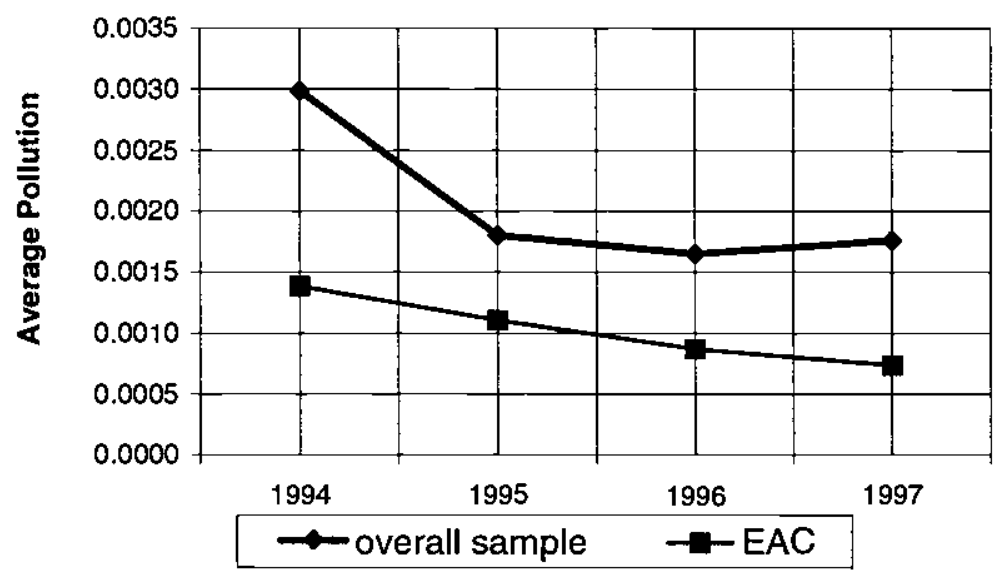

Fig. 8.5 The impact of information-based environmental policies; EAC companies vs. total sample in three selected industries worldwide, 1994-97

Note: See app. D; the average pollution has been calculated without considering the values of two outlier companies.

and gas); and PowerGen (electric power generation). According to our database and the scoring system, such companies were among the first to adopt EAC in their industries and to produce the highest quality CERs. We look at their environmental performances considering their emissions reduction rates before and after the EAC adoption. We also relate their emissions to the quality of the environmental information produced to see whether information quality and quantity are related to emissions reduction.

The analysis of emissions at BP Chemicals shows that the introduction of environmental awards and compensation programs did influence the pollution growth rate, which has been diminishing faster since the implementation of a pioneering award scheme in 1994. The negative trend in emissions, after a slowdown in 1995, was strengthened by the introduction of a certification and compensation scheme in 1996 (see table 8.3 and fig. 8.6).

ELF is an equally interesting case. The company sequentially introduced an award scheme in 1995, and a certification-compensation scheme in 1996, constantly improving its environmental performance (see table 8.3 and fig. 8.7). PowerGen adopted, in sequence, an environment-related award scheme, a compensation mechanism, and finally a certification system. Its emissions constantly diminished at increasing rates, from -0.084 percent in 1993-94 to -0.136 percent in 1994-97 (see table 8.3 and fig. 8.8). In these case studies, we can also observe a negative relationship between the quality of corporate environmental information and the emissions index. Figures 8.6, 8.7, and 8.8 illustrate these findings, highlighting the year of adoption of the various management tools. 
Average Growth Rate, 1993-94
Average Growth Rate with EAC, 1993-94

\begin{tabular}{lll}
\hline BP Chemical & -0.1202683 & -0.0204621 \\
ELF & -0.1074995 & -0.1729896 \\
PowerGen & -0.0842359 & -0.1358968 \\
\hline
\end{tabular}

Source: See appendix D.

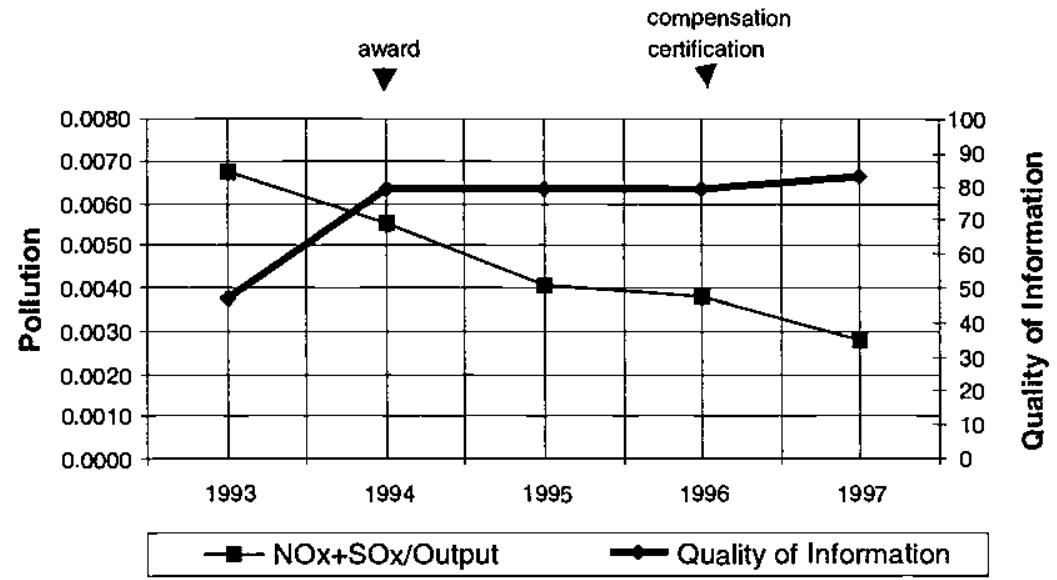

Fig. 8.6 BP Chemicals: the impact of information-based environmental policies, 1993-97

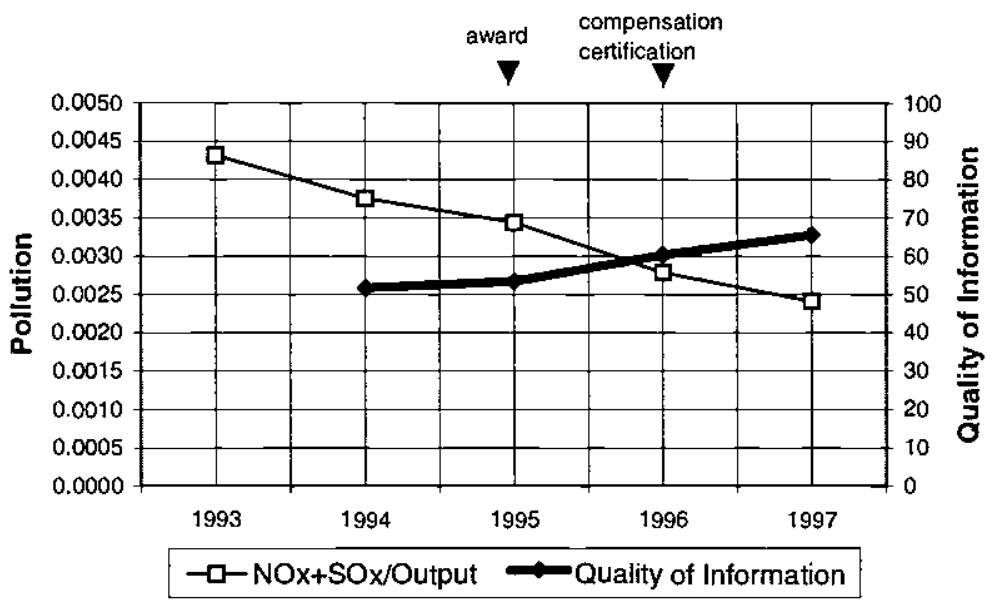

Fig. 8.7 ELF: the impact of information-based environmental policies, 1993-97 


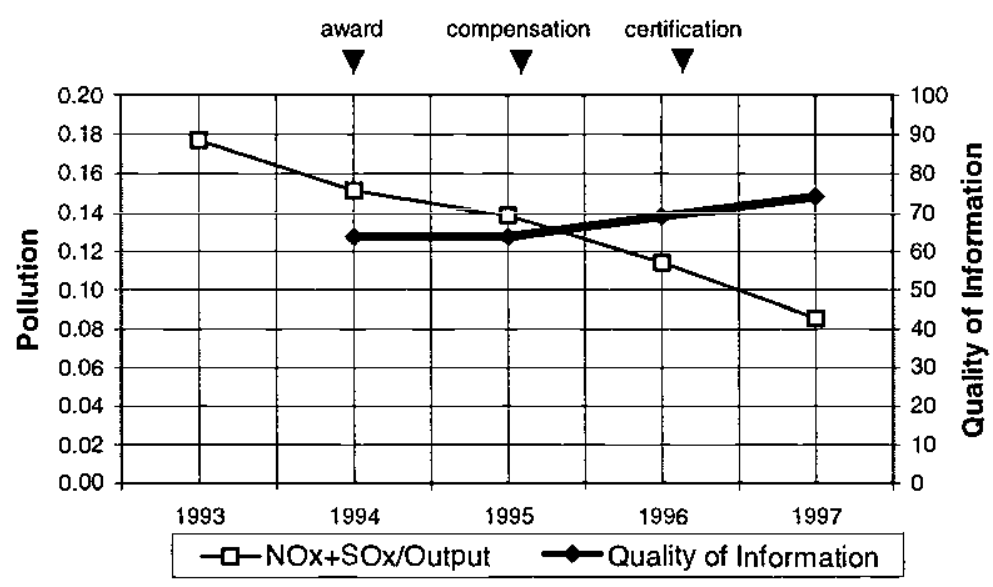

Fig. 8.8 PowerGen: the impact of information-based environmental policies, 1993-97

These results seem to be consistent with two ideas: (1) the adoption of information-based environmental tools improves company environmental performance, and (2) such management instruments are complementary with each other. Critics of information-based environmental strategies could object that our findings are possibly spurious because the analysis neglects standard environmental regulation, taxation, and several other variables that may influence emissions together with EAC. To overcome this objection, we carry out a statistical analysis that also includes other policy variables, together with some control variables. For this purpose, our panel is disturbingly small. But we believe that, at this stage, it is worthwhile to present, with many caveats, some tentative results.

\subsection{A Statistical Analysis}

We perform a cross-country analysis for 16 countries, assuming that governments adopt environmental policies based both on command and control and on economic instruments; and that companies comply and may also pursue tighter environmental strategies to avoid future risks and liabilities. In this setting, we check whether environmental policies (command and control instruments and energy taxation) affect the companies' economic and environmental performance. We also check whether the adoption of information-based environmental strategies (EAC) affects this relationship, influencing company behavior, given the energy tax burden and the severity of environmental legislation.

It is generally acknowledged that environmental policy reduces pollu- 
tion, but harms economic performance. This trade-off, however, can be eased by information-based environmental policies. We want to test whether these policies, which affect company behavior, can make compliance more effective and less costly. The variables used in our estimates are listed in table 8.4.

The model we want to estimate is a random-effects model that can be written as

$$
y_{i t}=\bar{\beta}_{1}+\sum_{k=2}^{K} \beta_{k} x_{k i t}+\varepsilon_{i t}+\mu_{i} .
$$

We estimate the model using an instrumental variable (IV) procedure because we cannot include all the variables simultaneously in our estimation because of the endogeneity of the operating income with the dependent variable. At first we estimate the link between operating income (OPERATING INCOME) and the existence of environmental certification, award, and compensation schemes (EAC), and the energy taxation burden (TAX). We take into account the company dimension by using the number of employees (WORK) as a control variable. Second, we relate the environmental performance of companies (the logarithm of company pollution, LPOLL) to the quality of environmental information at time $t-1$ (INFO) to their economic performance (the instrumented operating income, IOPINC) and to the enforcement of legislation (ENFORCE). The results are shown in table 8.5. As we expected, OPERATING INCOME is positively related to EAC and to WORK (the company size). INFO (the quality of environmental information) is nonsignificant.

Table 8.6 shows the results of the regression of the logarithm of com-

Table 8.4

Variables Used in Estimation

\begin{tabular}{|c|c|}
\hline Variable & Description \\
\hline AWARD & $\begin{array}{l}\text { Dummy, which is } 1 \text { when an environmentally based award program is } \\
\text { implemented }\end{array}$ \\
\hline CERTIFICATION & $\begin{array}{l}\text { Dummy, which is } 1 \text { when the company environmental management } \\
\text { system is certified for ISO } 14000 \text { and/or } 1836 / 96 \text { EMAS }\end{array}$ \\
\hline COMPENSATION & $\begin{array}{l}\text { Dummy, which is } 1 \text { when an environmentally based compensation } \\
\text { program at company level is implemented }\end{array}$ \\
\hline EAC & $\begin{array}{l}\text { Sum of CERTIFICATION, COMPENSATION, and AWARD (index } \\
0-3 \text { ) }\end{array}$ \\
\hline ENFORCE & Country index of environmental regulation enforcement \\
\hline INFO & $\begin{array}{l}\text { Index, which ranges from } 0 \text { to } 100 \text {, assessing the accuracy of company } \\
\text { environmental information }\end{array}$ \\
\hline LPOLL & Logarithm of company pollution, computed as $\mathrm{SO}_{\mathrm{x}}+\mathrm{NO}_{\mathrm{x}}$ per TOE \\
\hline OPERATING INCOME & Annual operating income in current U.S. dollars \\
\hline SECTOR & $\begin{array}{l}\text { Sectoral index, which is } 1 \text { for the electrical sector, } 2 \text { for oil and gas, } \\
\text { and } 3 \text { for chemicals }\end{array}$ \\
\hline TAX & Country index of burden energy taxes per GDP \\
\hline WORK & Number of employees per firm \\
\hline
\end{tabular}


Table 8.5

Operating Income

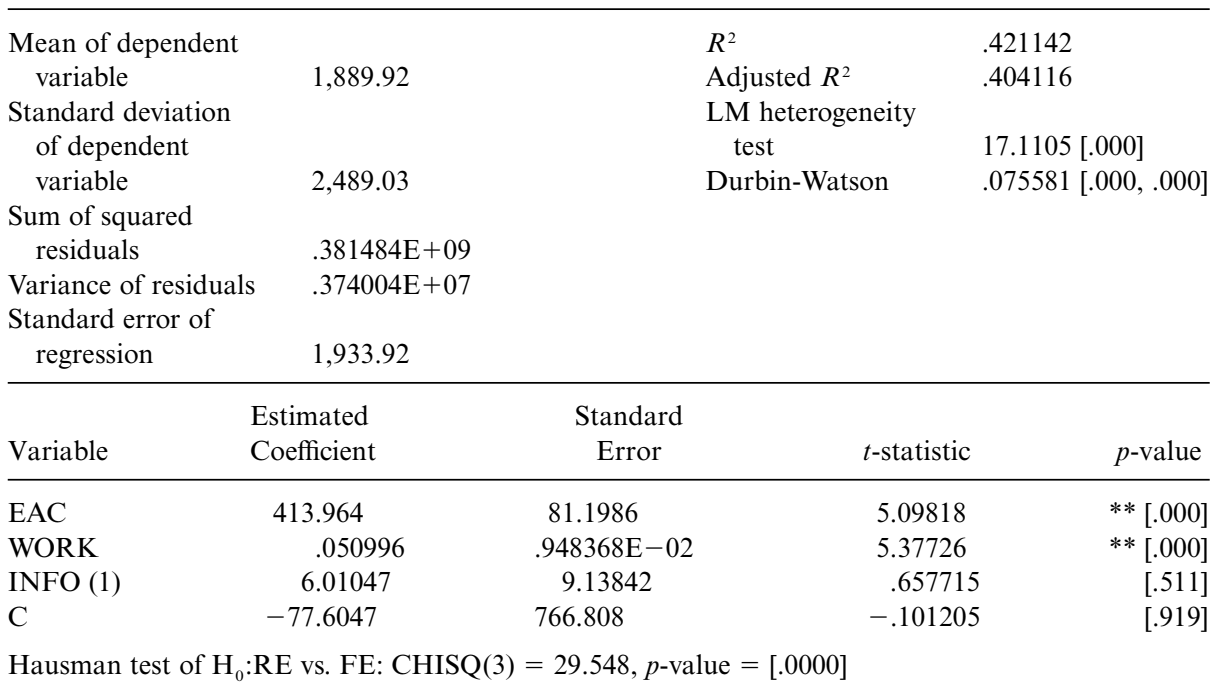

Table 8.6

Pollution (LPOLL)

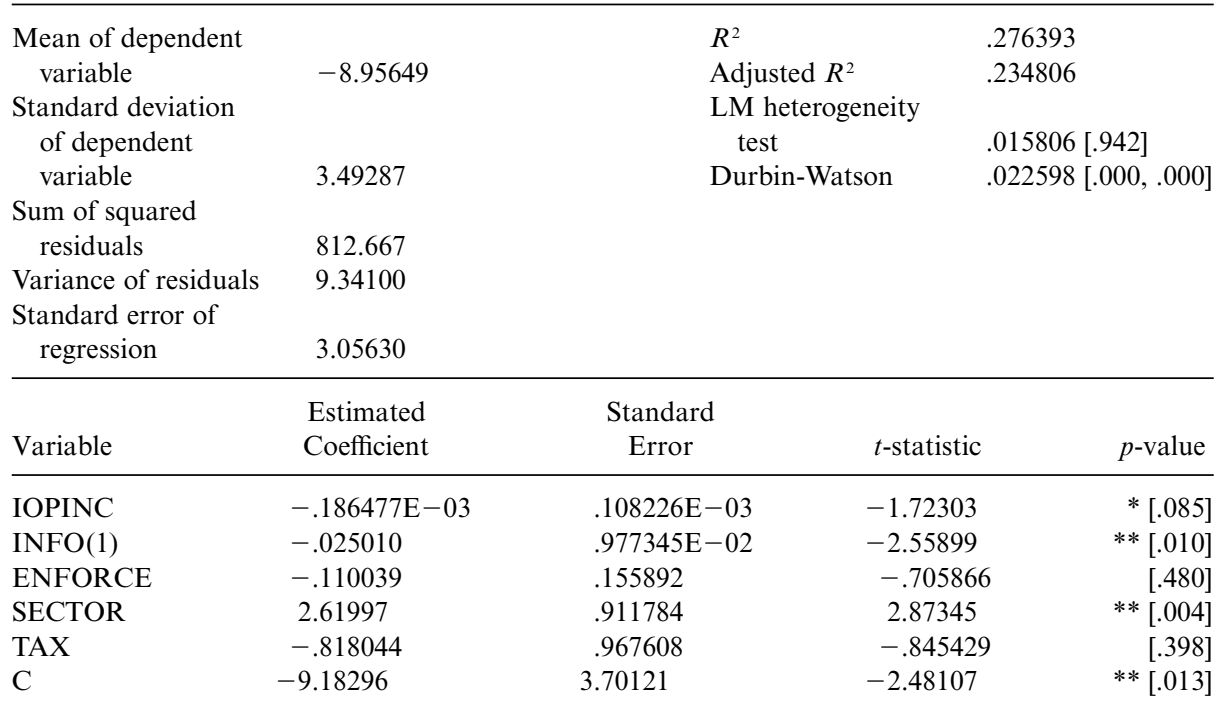

Hausman test of $\mathrm{H}_{0}: \mathrm{RE}$ vs. FE: CHISQ(2) $=5.2067, p$-value $=[.0740]$

pany $\mathrm{SO}_{\mathrm{x}}$ plus $\mathrm{NO}_{\mathrm{x}}$ emissions (LPOLL) at time $t$ on the instrumented OPERATING INCOME at time $t$, on the quality of environmental information (INFO) at time $t-1$, on the enforcement of legislation (ENFORCE), on the burden of energy taxation (TAX), and on the industry dummy (SECTOR). LPOLL is negatively related to IOPINC (the IV op- 
erating income), which is consistent with the idea that the adoption of EAC reduces emissions. Moreover, INFO (the quality of environmental information) is negatively related with LPOLL, suggesting that managers' and employees' efforts on environmental matters are significantly influenced not only by the presence of EAC but also by the accuracy of environmental information. SECTOR is positively related with LPOLL, simply reflecting the structural and technological characteristics of production in the three industries under review. Finally, the relation between ENFORCE and LPOLL is negative, but not significant ( $p=0.480)$.

\subsection{Concluding Remarks}

Information-based environmental strategies play a significant role in our sample. Given environmental regulation, which is costly, they positively influence operating income and negatively influence pollution. Being primarily implementation tools, they cannot substitute for more traditional policies, but can play a useful role.

Our findings are consistent with a whole class of models on environmental information, incentives, and company behavior. In our panel data estimation, the accuracy of environmental information is negatively related with pollution and the relation is significant. That is, information quality is crucial for companies' environmental management and there are explanations for corporate noncompliance that are not related to the level of the penalties, but instead to the company's scarcity of internal information (Brehn and Hamilton 1996).

In contrast from our results we cannot infer the role of environmental information accuracy on financial performance. In our analysis, we used operating income as a proxy of companies' financial health since we wanted to investigate the existing relation between environmental management tools and company results in the short period. Existing literature on environmental information and corporate financial performances finds a significant relationship between these variables, but it refers to external environmental information (information provided to external stakeholders) and to long-term performances such as shareholder value or liabilities (Tietenberg 1997; Lanoi, Laplant, and Roy, 1997; Khanna and Damon 1999). These differences help in understanding the differences between our analysis and prior analyses.

However, generic pleas for better and wider "environmental information" or "eco-management" are too vague and may be misleading. In order to exert a positive influence, environmental information needs to be integrated with a set of incentives, as recommended by economic theory for any company objective. This explains the nature of many integrated environmental and management schemes (such as ISO 14000 or EMAS) adopted by firms and recommended by policymakers. Our empirical 
model confirms the positive role of self-regulated environmental audits and compensation programs on corporate environmental performance, and this is consistent with an emerging research field that explores the possible patterns for integrating environmental issues with concrete management systems (Sinclair-Desgagné and Gabel 1997; Pfaff and Sanchirico 1999).

These conclusions, of course, are just tentative, given the preliminary nature of our empirical analysis. In order to reach more robust conclusions, better data must be collected and better estimates must be carried out. But the preliminary results we have obtained so far seem to be consistent with economic theory and with common sense. 


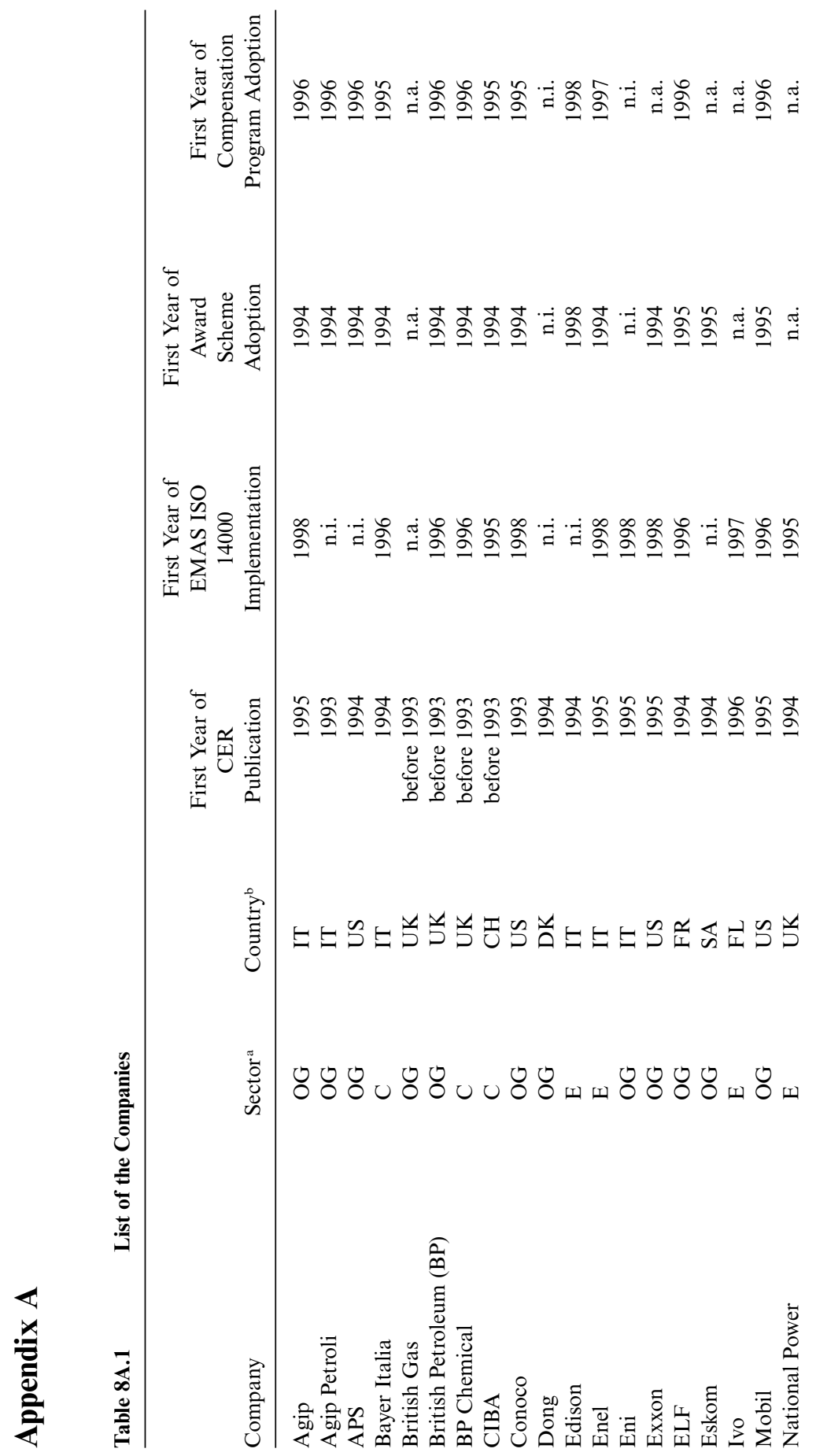




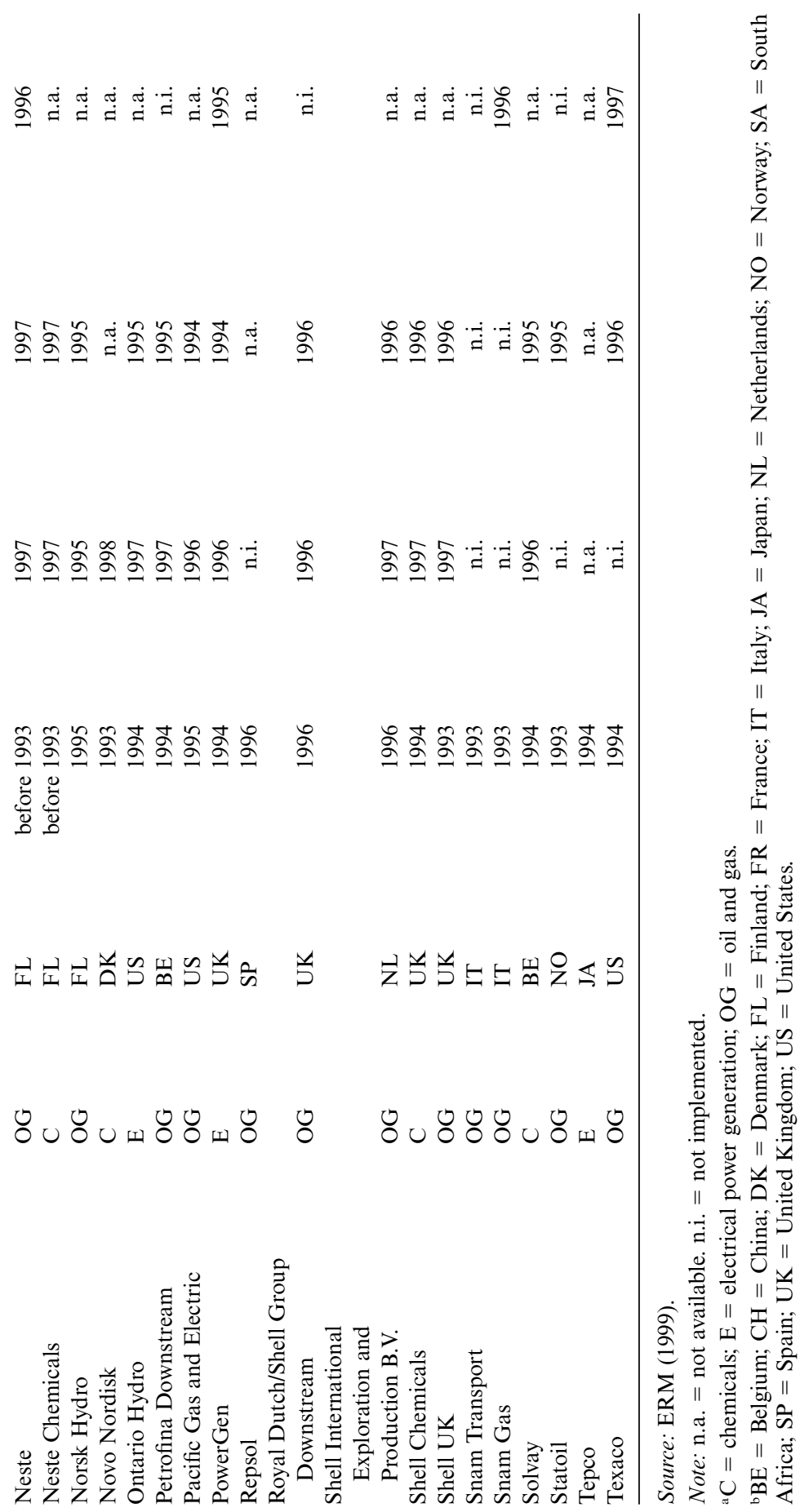




\section{Appendix B}

\section{Forum on Environmental Reporting Guidelines}

In order to guarantee a minimum standard of CERs as a voluntary document, FEEM organized in 1994 the Forum on Environmental Reporting (FER) by inviting some large companies emerging in the field of environmental management and reporting, and some interested target groups for environmental reports, environmental groups, and public administration, to work together to draw up guidelines. The aim of the FER is to set guidelines for companies seeking to produce an effective environmental report, providing stakeholders with the information needed from other similar initiatives for a consensus approach. Here follows the list of minimum and recommended requirements to be included in CERs. These requirements have been used as the basis for the ERM scoring system, aimed at evaluating the quality of environmental information.

Qualitative Information (Notes to the Environmental Balance Sheet)

1. Company description

a. Company size and activities

b. Number and location of production sites

c. General description of production processes

d. Description of the main environmental issues related to production and distribution

2. Environmental policy

a. Year of introduction of environmental policy and content

b. Expected achievements

c. Achievements monitoring (comparison with prevous reported objectives)

3. Environmental management systems

a. Organization structure (environmental department and relationships with other business units)

b. Programs for environmental policy implementation

c. Training activity

d. Implementation level of environmental management system and certifications (EMAS, ISO, or UNI [Ente Italiano per l'Unificazione])

4. Risk management

a. Audits, mesaures taken, and achievements regarding risk management

b. Description of cleanup operations carried out

c. Description of major accidents

5. Compliance with environmental legislation

a. Description of the way the company ensures compliance with environmental regulations (in relation to previous violations as well as to prevention measures)
Minimum requirement

Minimum requirement

Minimum requirement

Minimum requirement

Minimum requirement

Minimum requirement

Minimum requirement

Minimum requirement

Minimum requirement

Recommended requirement

Recommended requirement

Recommended requirement

Recommended requirement Recommended requirement

Recommended requirement 
b. Description of measures adopted to comply with new environmental regulations (EU, national, and local) that became operational during the period to which the report refers

6. Product policy

a. Description of product's life cycle and of the related impacts and description of the most relevant measures to mitigate them

b. Product innovation

c. Product's energy efficiency (when relevant)

d. Company responsibility at the end of product use

e. Cooperation programs with consumers and clients

f. Ecolabel (where applicable)

7. Conservation of natural resources

a. Energy-saving programs

b. Water-saving programs

c. Other programs for the protection of natural heritage

8. Stakeholders' relations

a. Participation in voluntary agreement schemes

b. Relations with stakeholders (public administration, environmentalists, universities, etc.)

c. Department or name of the person to contact for further information

9. Certification

a. External certification

b. Certification by EMAS-accredited verifiers
Recommended requirement

Recommended requirement

Recommended requirement Recommended requirement Recommended requirement Recommended requirement Recommended requirement

Minimum requirement

Minimum requirement

Recommended requirement

Recommended requirement

Recommended requirement

Minimum requirement

Recommended requirement Recommended requirement

\section{Table 8B.2}

\section{Quantitative Information (the Environmental Balance Sheet)}

1. Environmental expenditures

a. Data on environmental expenditures

b. Explanation of accounting criteria

2. Emissions and consumption of raw materials

a. Site-by-site quantitative information (for main sites)

b. Raw materials

c. Energy as input

d. Wastes, air emissions, water discharges, soil pollution, and other pollutants relevant to company's activity

e. Quantity of products or a relevant figure to describe production level

f. Impacts (scientifically accounted) related to production activity

g. Reduction objects for raw materials, energy, pollutants, and impacts

3. Environmental performance indicators

a. Environmental performance indicators compared with previous periods
Recommended requirement Minimum requirements

Minimum requirement

Recommended requirement Minimum requirement

Minimum requirement

Minimum requirement

Recommended requirement

Recommended requirement

Minimum requirement

Source: FER (1995). 


\section{Appendix C}

\section{Environmental Reporting Monitor (ERM)}

Starting from the Forum on Environmental Reporting (FER) guidelines the FEEM has set up an Environmental Reporting Monitor (ERM) defining a three-section checklist as a scoring system. The first two sections represent of the two parts of the report: the first section checks for the qualitative information, the second one for the quantitative information, following the FER requirements (see FER 1995, app. 3); the third one is the comments section, explained here. The structure of the checklist is as follows:

- Qualitative section: It verifies that four minimum requirements and eleven recommended requirements are met. The score-the report can receive from 0 to 2 points for every minimum requirement met and from 0 to 1 for every recommended requirement met.

- Quantitative section: It verifies that nine minimum requirements and five recommended requirements are respected. The score-the report can receive from 0 to 2 points for every minimum requirement respected and from 0 to 1 for every recommended requirement respected.

- Comment: First, it checks that the CER structure complies with the FER guidelines. Then, it checks whether the report is complete. The score for data quantity - if it is exhaustive it receives 2 points, if medium 1 point, if it is not enough 0 points. The score for data qualitywhether the CER refers to a sample, whether the report maker used a specific methodology for CER data collection, and whether an audit has been implemented to check the data from 0 to 2 points. Then it checks report legibility (from 0 to 2 points), and it verifies whether the report gives other information and whether there is a positive evolution in act from the last reports to the present one (if yes, 1 point).

Each CER can receive up to 19 points in the qualitative section, 23 points in the quantitative section, and 16 points in the comments section. The maximum score is 58 points. For this paper, each score has been normalized. 


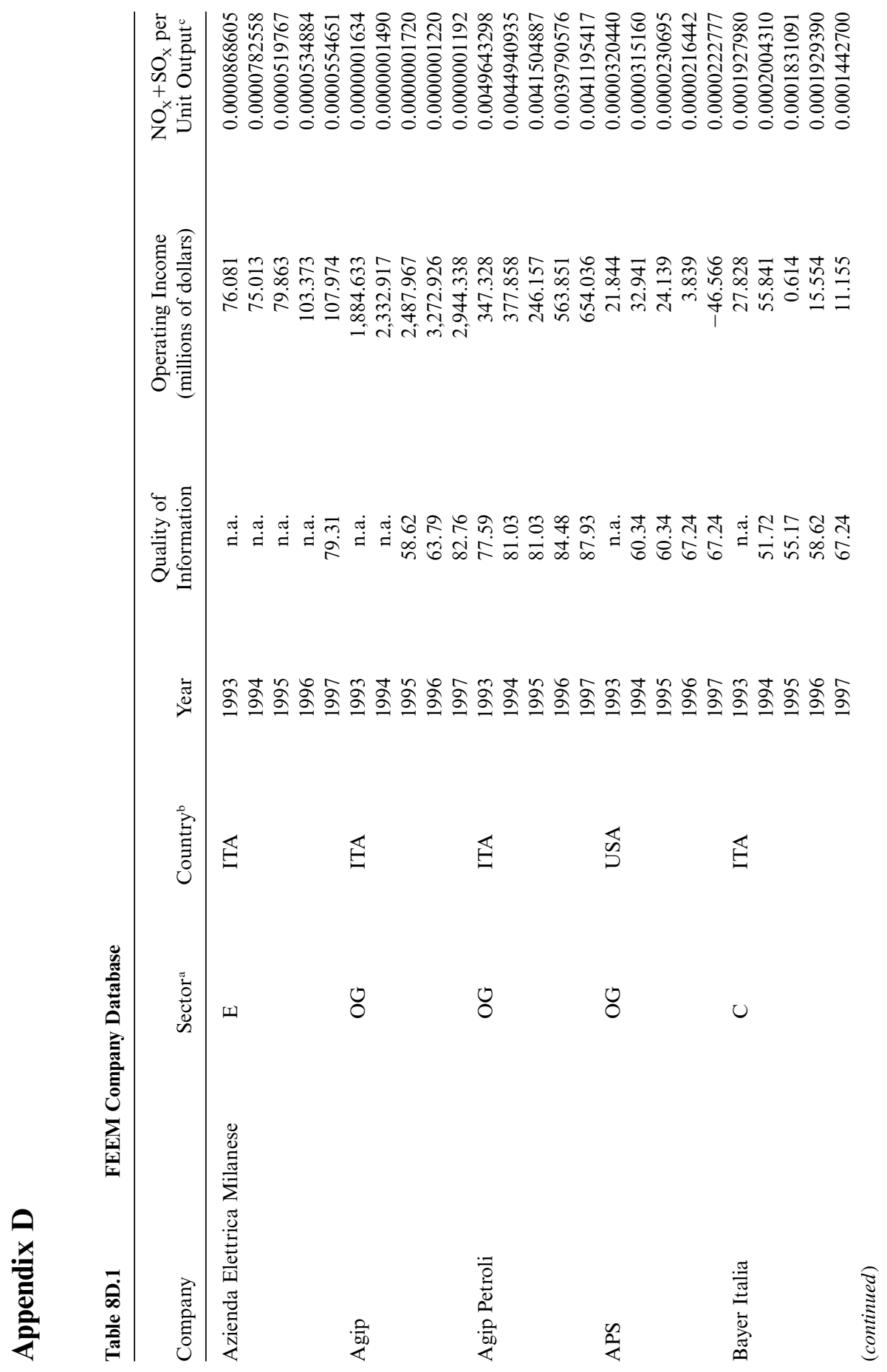




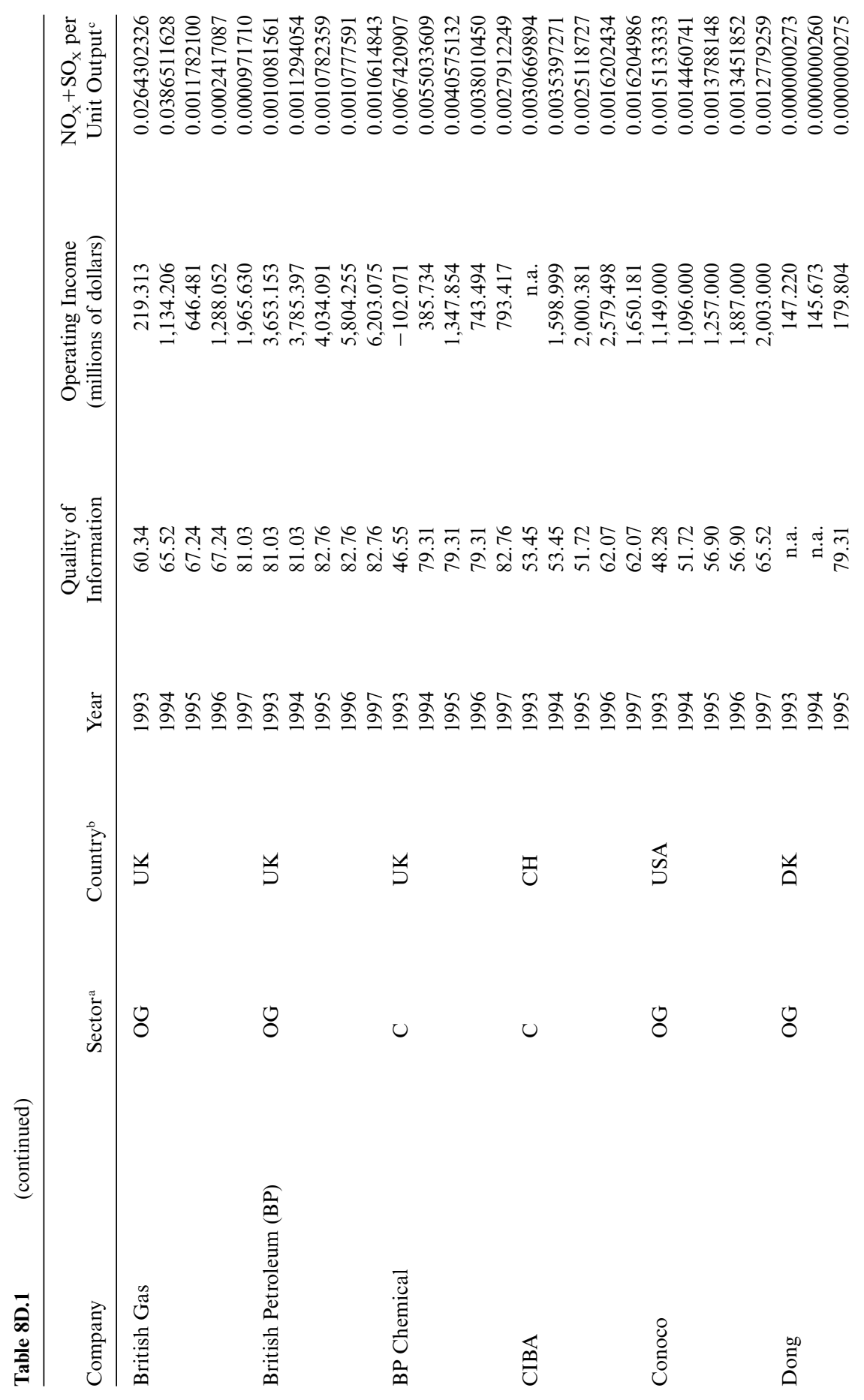




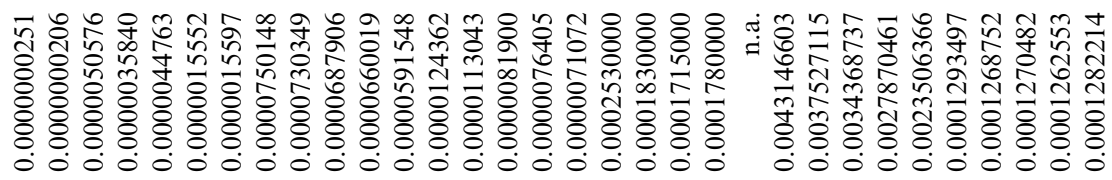

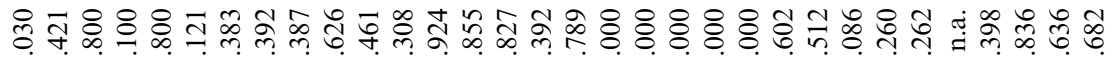

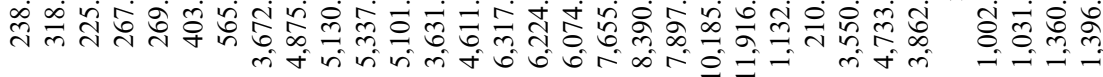

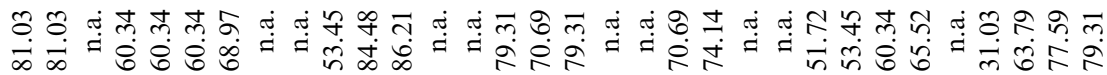

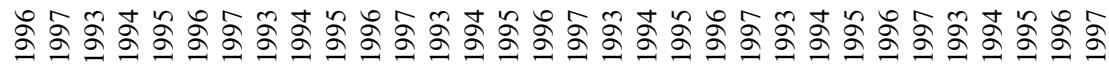

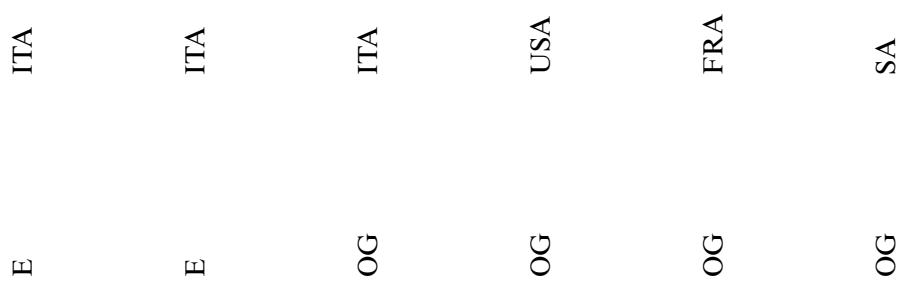

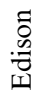

馬

是

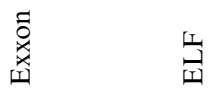

$\frac{\text { Eี }}{\frac{1}{4}}$ 


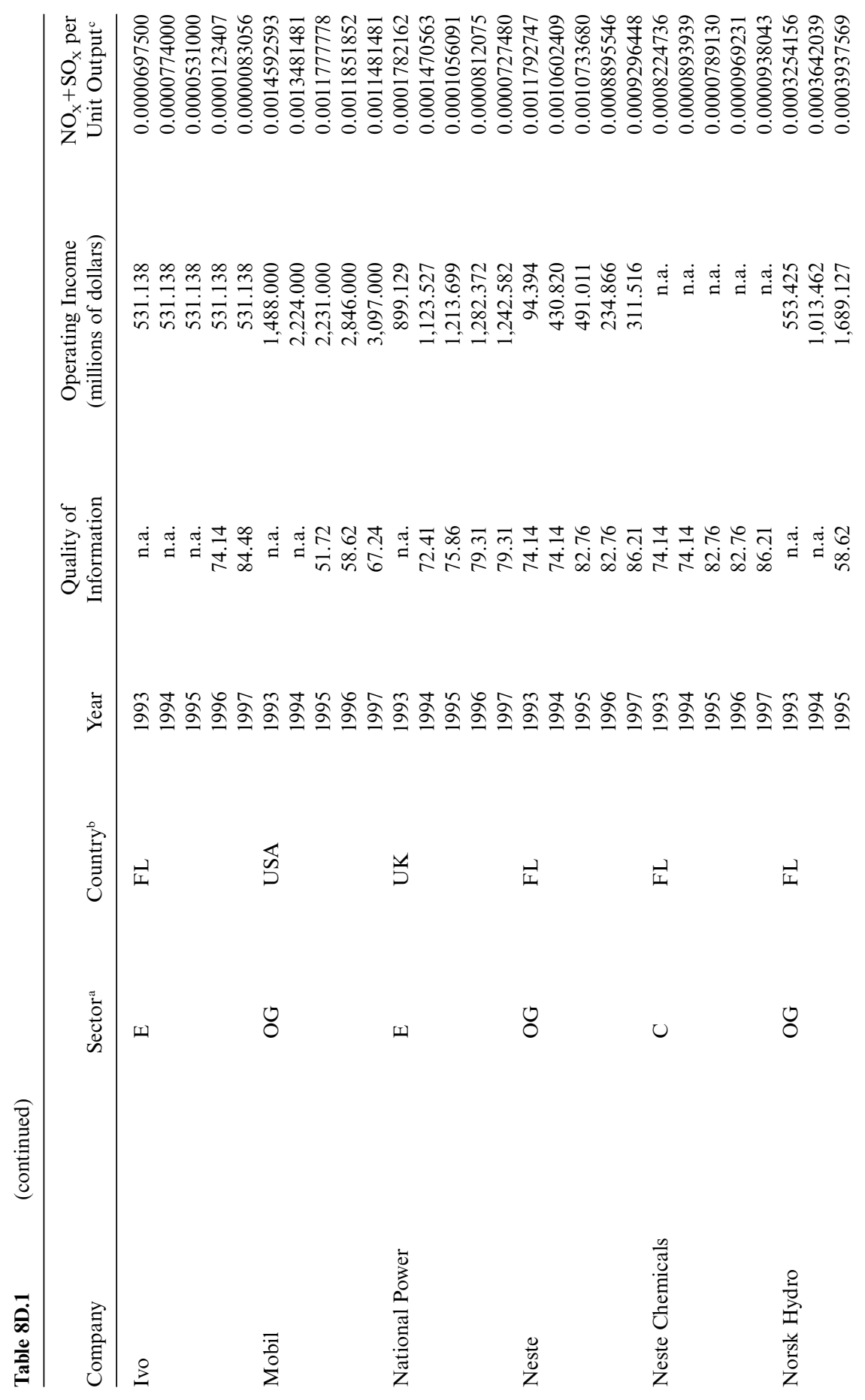




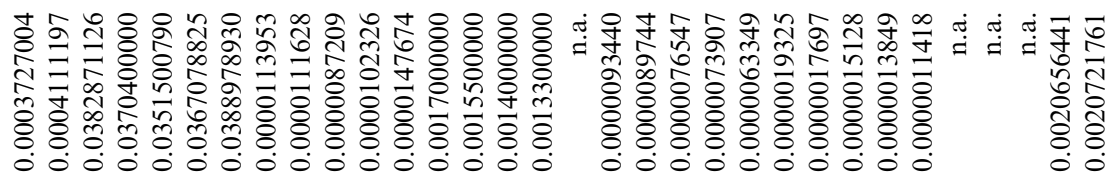

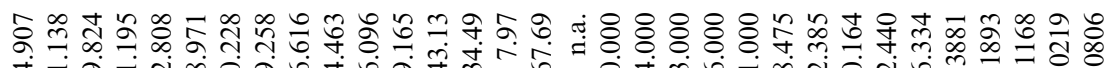

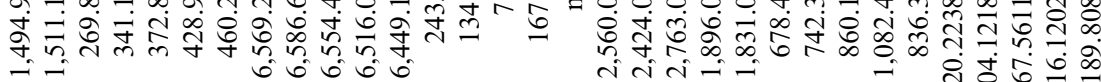
तิ

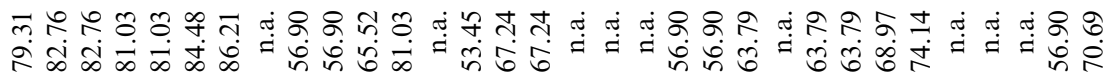

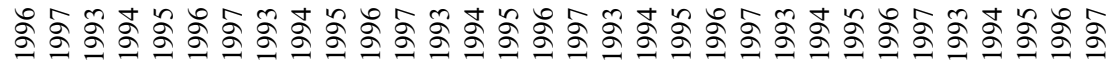

兑

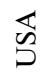

$\stackrel{1}{\infty}$

$\sqrt{3}$

亭

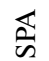

○

山

8

8

山

¿

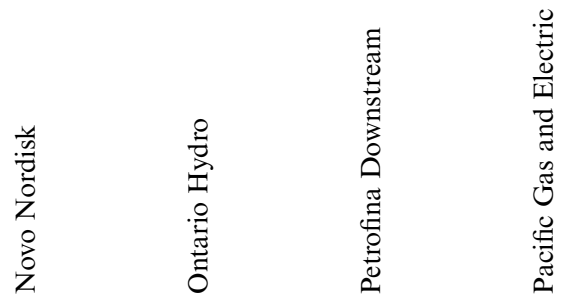

ญี

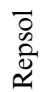




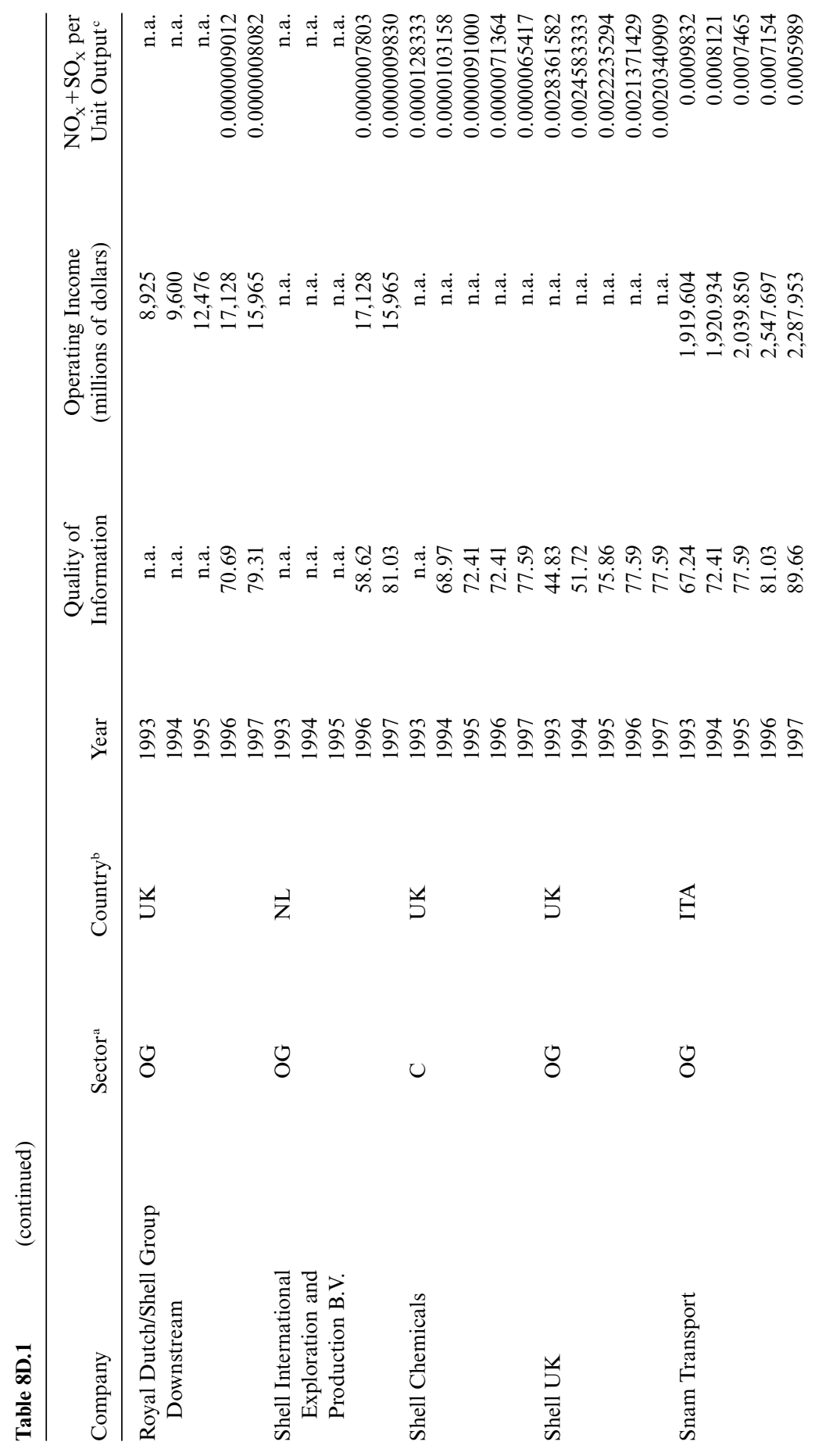




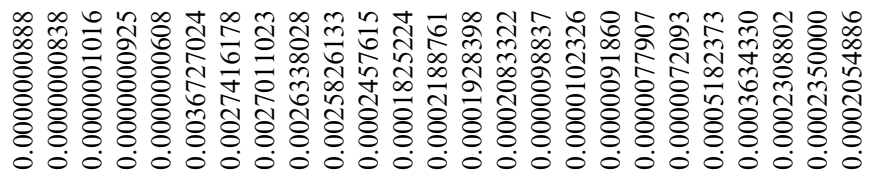

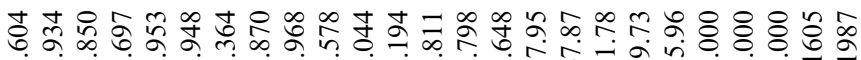

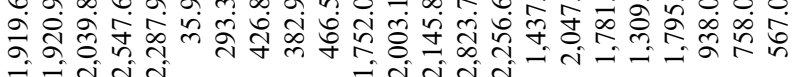

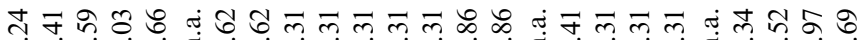

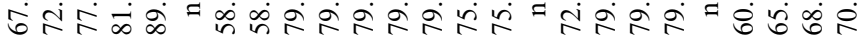

O

8

8

8

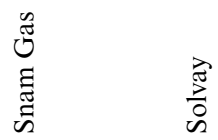

$\overline{\bar{c}}$

$\stackrel{8}{\stackrel{0}{0}}$

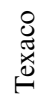




\section{References}

Brehn, J., and J. T. Hamilton. 1996. Non compliance in environmental reporting: Are violators ignorant or evasive of the law? American Journal of Political Science 40 (2): 444-77.

Environmental Reporting Monitor (ERM). 1999. Database and analysis from 1995. Milan: Fondazione Eni Enrico Mattei.

Forum on Environmental Reporting (FER). 1995. Corporate environmental reporting guidelines. Milan: Fondazione Eni Enrico Mattei.

Khanna, M., and L. Damon. 1999. EPA's voluntary 33/50 program: Impact on toxic releases and economic performance of firms. Journal of Environmental Economics and Management 37 (1): 1-2.

Lanoi, P., B. Laplant, and M. Roy. 1997. Can capital markets create incentives for pollution control? Policy Research Working Paper no. 1753. Washington, D.C.: Environment, Infrastructure and Agriculture Division, World Bank.

McIntosh, M., D. Leipziger, K. Jones, and G. Coleman. 1998. Corporate citizenship. London: FT Pitman.

Musu, I., and D. Siniscalco. 1993. Ambiente e contabilità nazionale. Bologna: Il Mulino.

Pendergast, C. 1999. The provision of incentives in firms. Journal of Economic Literature 37:7-63.

Pfaff, A. S., and C. W. Sanchirico. 1999. Environmental self-auditing: Setting the proper incentives for discovery and correction of environmental harm. Columbia University School of International and Public Affairs. Working paper.

Sinclair-Desgagné, B., and L. Gabel. 1997. Environmental auditing in management systems and public policy. Journal of Environmental Economics and Management 33:331-46.

Tietenberg, T. 1997. Information strategies for pollution control. Paper presented at the eighth annual European Association of Environmental and Resource Economists conference, Tilburg University, The Netherlands, 26-28 June.

\section{Comment Kevin Hassett}

It is all too often the case in economics that researchers spend far more time devising elaborate methods to tease answers from existing data sets than they do performing the heavy lifting required to develop new data sources. This paper is a refreshing contrast. The authors have built a fascinating database that will be an invaluable resource to future researchers, who will likely be able to shed new light on a number of interesting questions with these new data.

When I teach econometrics to graduate students, I always try to emphasize the potentially large benefits from developing new data: One can often learn a great deal with a simple inspection of sample means. If I have a criticism of this paper, it is that the authors have taken this point a little 
bit too literally. After developing their new data, they seem to have run out of gas, providing only a cursory set of simple regressions that are very poorly documented. Clearly, much work is left to be done, and readers might better spend their time staring at the individual observations presented in the appendixes than reading the empirical section carefully.

Now for the details. Many economists have long feared that managers have little incentive to worry too much about how much pollution their firm produces. Cutting back pollution is costly, and since managers' compensation depends on near-term profits, there is little incentive to be too aggressive. Costs from pollution are often long term, and the manager will be floating on his yacht in the Mediterranean by the time the firm has to pay for the damages its pollution has caused.

Regulators, and to some extent firms, have recognized this problem, and a number of complementary approaches have been adopted to overcome it. Recognizing that shining a light on pollution as it occurs might increase incentives to internalize long-run costs, the European Commission adopted the EMAS (Eco Management Audit Scheme), which recommends a method for evaluating the environmental performance of a firm. In addition, many firms have begun to increase executive compensation when particular environmental targets are met by management. The question is, are these measures effective? Does pollution go down when the policies are adopted?

Ex ante, there is no reason to believe that they would be effective. Information concerning effluents that is supplied voluntarily might be very unreliable. Managers may enjoy receiving bonuses for green behavior, but the monetary rewards of high profits are significant, and one might expect them to dwarf the bonuses associated with environmental performance.

To address the question, the authors constructed a database from firm environmental reports published from 1993 to 1997. They selected a sample that includes all the companies belonging to three polluting industries: petrochemicals, oil and gas, and electric power generation. The final sample consists of 39 firms based in 16 countries. The authors first show that firms that adopt reward schemes have slightly better environmental performance, although the difference is not statistically significant. Pollution decreases over time faster for firms that have incentive programs as well, but again the evidence is fairly weak.

The authors then perform a statistical analysis that proceeds in two steps. They show that operating income is higher for firms that have environmental compensation programs, and then show that pollution is lower for firms that have better environmental reports.

It is at the estimation stage that the work starts to have problems. It is not clear to me what the authors are attempting to establish by running a regression with a limited number of variables to predict operating income. None of the variables is scaled or, as far as I can tell, deflated, so that 
strong trends in the data (or swings in exchange rates) could be determining the results. A sign that trouble is afoot is the Durbin-Watson, which is very close to zero. With very strong trends in the data, there is almost certainly a spurious regression problem, and the $t$-statistics are essentially meaningless. So do these programs affect environmental performance? Should governments everywhere start to require better environmental audits and green compensation packages? It is impossible to say given what has been done here because the empirical work is incomplete.

A more thorough empirical analysis of the data here will be quite promising. A good place to start would be to perform some simple differencein-difference comparisons that build on the work presented in table 8.2. Clever use of this technique should overcome the biggest empirical problem here: Firms that adopt programs might have a strong taste for environmental reform, and this unobserved heterogeneity might make it look like the program is effective, when in fact the program is only a signal of the firm's underlying preferences toward pollution.

Despite these criticisms, I enjoyed the paper very much. The authors have provided the profession an invaluable service in constructing the data set (and carefully describing the programs), and they should be commended for printing the entire data set in the appendixes. 